\title{
THE GENOMICS EVOLUTION
}

\section{As a result of the need to transform into drug discovery companies, genomics companies have had to change their recruitment models.}

Simon Frantz, Associate Editor (News), Nature Reviews Drug Discovery e-mail:s.frantz@nature.com
The beginning of the current millennium witnessed the seemingly unstoppable progress of genomics companies. With the promise of better-defined disease targets and pathways leading to more efficacious and less toxic drugs, their technology platforms were being hired out to most large pharmaceutical companies all eager for the windfall of information that genomics promised. As the first draft of the human genome sequence neared completion in 2000, stock prices of genomics companies shot up to record levels, and the biotechnology industry raised $\$ 32$ billion through stock offerings that year.

But only a year later, and with the publication of the human genome sequence from the public consortium and Celera in hand, share prices had fallen by $70 \%$ and fell another 50\% the following year.

Despite the wealth of validated targets, few companies could convince investors impatient for returns that they could generate and sustain profits from their initial business models. The 'genes-to-drugs' model of genomics companies made sense initially, but the reality was that these technology platforms were still only target-validation tools and were therefore addressing only one bottleneck in the drug discovery and development pipeline.

Companies such as Human Genome Sciences (HGS) and Millennium pioneered the changes that were necessary for genomics companies to survive. To maximize their value, these companies switched from licensing their technologies to developing drugs, either in-house or through acquisitions. Unlike other biotechnology start-ups, many genomics companies had the advantage of financial support to develop their successfully validated targets into drug discovery programmes, as they had cashed in on some of their stock when it was at its peak, and had the competitive advantage of intellectual property rights on gene sequences.

Now, genomics companies are pursuing every option available for drug development: purchasing or creating the necessary chemistry expertise, such as Millennium, Vertex and Lexicon Genetics, or in-licensing or developing biologics, such as HGS and Curagen.

The effects of the evolution from genomics to drug discovery companies on the recruitment market are twofold. First, after a period of ramping up recruitment in the past few years, the market has flattened out, and indeed dipped, as companies are consolidating. Few companies have avoided reducing their workforce in an effort to contain costs and re-focus drug development efforts. The recent restructuring of HGS seemed to sum up this evolving model - as well as cutting its workforce and pipeline, the company's talismanic founder and CEO, William Haseltine, announced his retirement, saying that HGS needed a leader with more experience in late-stage drug development.

The second effect is that the shift in emphasis from front-end research to more downstream drug development processes has led to a changing recruitment model. Academic institutions are steeped in genomics- and biology-based expertise, but practical experience of medicinal chemistry, pharmacology and clinical trials is now required to develop compounds of therapeutic interest and drugs that are already in clinical development (FIG. 1). Companies are therefore increasingly looking to industry to fill positions - and there is no shortage of appropriate candidates. Merger activity has flooded the recruitment market with such expertise as a result of downsizing and rightsizing - recruiters from genomics companies say that the number of industry applicants for these positions has grown noticeably in the past 12 months. Faced with an almost embarrassment of riches in expertise, genomics companies are increasingly using active recruitment processes to hire candidates from relevant disease areas, and in particular those hungry to bring their industry experience to a smaller and more dynamic setting.

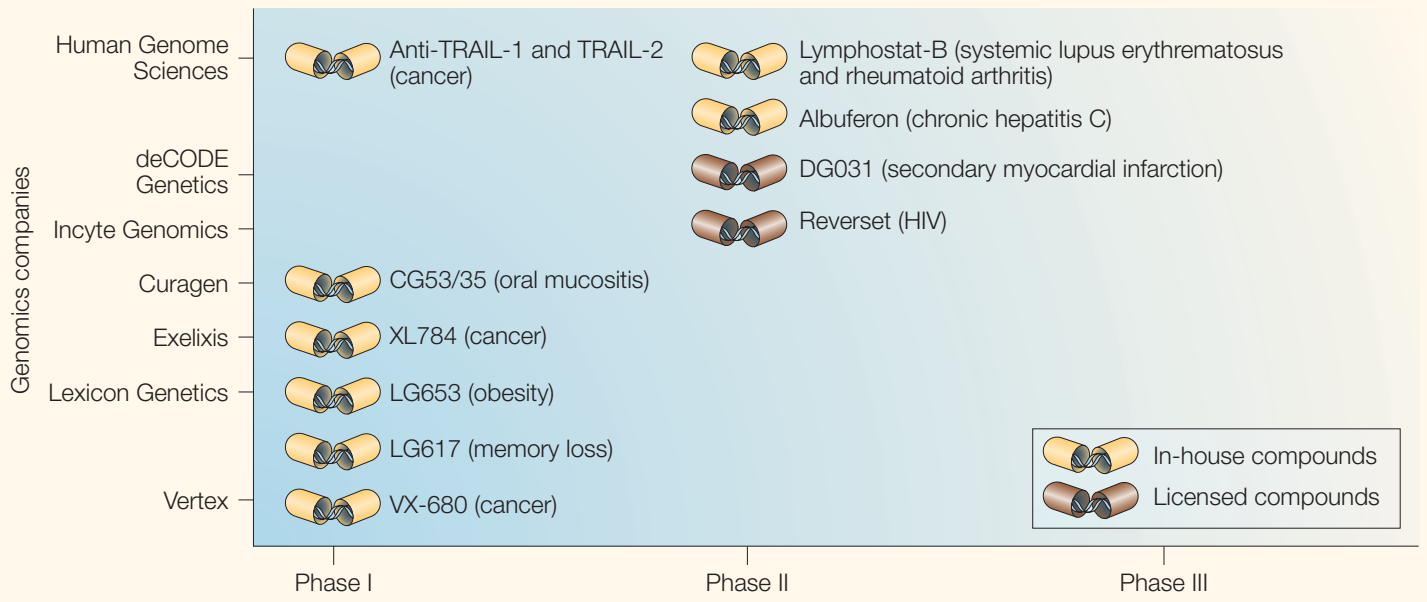

Figure 1 | Selected genomics-derived drugs in clinical development. Treatment indications are in brackets. 